\title{
The Methods and Meanings of Collaborative Team Research
}

\author{
Serin D. Houston', Jennifer Hyndman², \\ James McLean ${ }^{3}$, and Arif Jamal ${ }^{4}$
}

\begin{abstract}
Team research enables the collection of multiple, sometimes conflicting, stories of migration, family, and belonging. Using common qualitative methods within a team research context can stretch these research techniques in productive and instructive ways and proffer new insight and meaning. Therefore, the authors suggest that team research offers an important avenue for both extending qualitative methods and expanding interpretative lenses. To illustrate these points, the authors draw upon their study of the settlement and migration patterns of East African Shia Ismaili Muslims in Vancouver, British Columbia, Canada, and discuss their experiences with focus group effects, the simultaneous household interview strategy, and postinterview dialogues. The article highlights how these three techniques and effects enacted in the team research context helped the authors explicitly locate contradictions, ambiguities, and paradoxes within the narratives of first- and second-generation Ismailis.
\end{abstract}

\section{Keywords}

collaborative team research; focus groups; household interviews; Ismailis; qualitative methods

"Team Ismaili"" is a group of four geographers (at the time two master's students, one professor, and one instructor), who joined together as research collaborators in the summer of 2005 to explore transnational migrations and connections, family and community expectations, and identity expressions among East African Shia Ismaili Muslims ${ }^{2}$ in Greater Vancouver, Canada. We approached these themes through focus groups and in-depth individual interviews with Ismailis who either forcibly or voluntarily left East Africa between 1970s and early 1990s (people we defined as first-generation Ismailis) and the adult Canadian-born children of these immigrants (defined as second-generation Ismailis). ${ }^{3}$ The contrasting and complementary stories of "Ismaili-ness" evident in the research archive grew to be a compelling focus within our study and prompted us to reflexively consider how our methods contributed to the gathering of disparate accounts. Therefore, in this article we discuss our experiences with focus group effects, the simultaneous household interview strategy, and postinterview dialogues. We highlight how stretching qualitative methods through the team research context helped us explicitly locate contradictions, ambiguities, and paradoxes within the narratives of first- and second-generation Ismailis. In other words, the meaning of the narratives about the Ismaili community became nuanced and textured through the teambased mobilization of our methods.
The three methodological engagements that we discuss here provide the foundation for this article. With this in mind, first, we detail the literature on focus groups and discuss the emergence of various focus group effects in our research. We next turn to the simultaneous household interview strategy and outline how this technique offers glimpses into assorted intergenerational perspectives (Jamal, 2006; Pang, 1998). We conclude with examples from our postinterview dialogues. This structure mirrors the organization of our field research in that we first conducted focus groups and then held household interviews. After several household interviews we started debriefing through the postinterview dialogues. While Easterby-Smith and Malina (1999, p. 77) described the "need to adapt methods for different national and cultural circumstances," in this examination of our research modalities, we show that collaborative team research itself provides an important avenue for both adapting qualitative methods and expanding interpretative lenses. In a different but related article, we examine the creation of our team, our collective and individual positionalities, the challenges and successes we experienced, and

\footnotetext{
'Syracuse University, New York

${ }^{2}$ York University, Toronto, Ontario, Canada

${ }^{3}$ York University, Toronto, Ontario, Canada

${ }^{4}$ Canada Border Services Agency, Ottawa, Ontario, Canada
} 
the implications of this team formation on knowledge production (Houston, Hyndman, McLean, \& Jamal, in press; see also Hafernik, Messerschmitt, \& Vandrick, 1997; Pushor, 2008, pp. 92-93, for an explanation of the characteristics of collaborative research). Here we train our attention to the research techniques and effects expressed during fieldwork to illustrate how common qualitative methods, such as interviews, can take on new forms within the team research context.

Before we continue on to the substantive aspects of our exploration, a brief note about our terminology: In a weekly team meeting during the flurry of fieldwork, we coined the phrase "focus group effects" to describe the many ways that experiences in, and narratives from, the focus groups seeped into the individual interview contexts. At times, the focus groups were just a point of reference in interviews; in other instances, they served as a point of comparison; and in still other moments, they provided the tacitly agreed upon dominant community narratives, which were upheld and reproduced in the interviews. We sought to collectively identify and examine the traffic between focus groups and interviews, and the phrase "focus group effects" helped us begin to highlight these connections (Houston, Hyndman, Jamal, \& McLean, 2006).

We elected to conduct simultaneous (rather than serial) interviews with different household members so as to provide space for potentially divergent narratives of family, migration, home, and identity to arise. ${ }^{4}$ This technique, which we call the simultaneous household interview strategy, relied entirely on teamwork as we individually interviewed different household members at the same time. The simultaneous household interview strategy infused our archive with numerous perspectives as we gathered a host of different stories. These assorted renderings helped fracture essentialized portrayals of the Ismaili community.

The diverse narratives gleaned through household interviews generated the use of another team-based qualitative method, namely, postinterview team dialogues. In these discussions, which we started to record and transcribe, we revisited our individual interviews to piece together a wider understanding of a household. These debriefing sessions occurred right after the interviews so perceptions were still fresh. Indeed, this collective analytical space grew out of the household interview setting. The postinterview dialogues exposed the divergent perceptions of family members from one household and worked to consistently disrupt any singular narrative of a family or the Ismaili community. They also encouraged us to take seriously the mixed interpretations and perspectives we assembled.

The relevance and importance of teamwork to research design, data collection, and knowledge production underpins this analysis. We could not have done this kind of research individually, and most likely, we would not have been able to invite such ambiguity and variability into our archive if we mobilized a different research configuration. Hafernik et al. (p. 31) explained that by "extending the circle of researchers, we broaden the perspectives and add voices to the field." In addition to highlighting multiple ways of knowing, working as a team enabled us to practice qualitative methods in different ways. When the goal underlying a project is to unpack manifold expressions of identity or social and familial relations, it becomes necessary to adopt methods - or a mixture of methods - that also emerge from a commitment to garnering several interpretations. For us, the team research context made these methodological extensions and modifications feasible. Moreover, as the following discussion intends to demonstrate, teamwork shed light on the exciting ways that research designs can shift and grow and the subsequent ramifications for knowledge production. While we know that collaborative team research often indicates partnerships between academics and community members or participatory action research (Hafernik et al., 1997; Pushor, 2008), in our situation we use this phrase to refer to the collaboration evident between the four of us, the members of Team Ismaili.

\section{Featuring Focus Groups}

Focus groups generally involve 4 to 12 participants-at times strangers and at times friends and coworkers - who a researcher or research team recruits and gathers together to collectively discuss a set of ideas and topics determined by the researchers (Conradson, 2005; Holbrook \& Jackson, 1996; Morgan, 1996, 2002; Skop, 2006). Goss (1996, p. 113) added that focus groups can also offer a space for situating a researcher within a new community, generating testable hypotheses, piloting future survey questionnaires, theory building, crafting plans for social action, and sharing results with a community (see also Kamberelis \& Dimitriadis, 2005). Where rapport and trust are absent, focus groups are a way of accessing initial responses in a safe and supportive environment, especially because certain groups, such as refugees, often carry a deep suspicion of the state and university researchers as perceived representatives of the state (Hyndman \& Walton-Roberts, 2000; McLean, Friesen, \& Hyndman, 2006).

Although sociologists used focus groups during World War II (Cameron, 2000, p. 86), the method did not gain significant traction within the social sciences until the last 20 years (Burgess, Limb, \& Harrison, 1998; Kamberelis \& Dimitriadis, 2005; Morgan, 2002). During this time of renewed interest, scholars have relied upon focus groups in research contexts as diverse as understanding experiences of pregnancy (Longhurst, 1996) to evaluating educational pedagogies (Breen, 2006) to deepening interpretations of multiracial communities (Skop, 2006). Building upon this 
empirical diversity, some scholars have also explored the different kinds of generative effects and histories of focus groups. In particular, Kamberelis and Dimitriadis (p. 889) suggested that focus groups work as "as critical pedagogical practice, ... as political practice, and . . . as research practice."

Focus groups range from highly structured to fairly flexible and fluid designs, but the potential for synergy among participants is what makes the method particularly attractive to social science researchers. The facilitator plays a central role in the success of a focus group. How well the facilitator listens, helps establish trust, negotiates conflicts, reflects perspectives, and keeps the group on task will inform the outcomes (Burgess et al., 1988). Other key facets of focus group facilitation include the ability to probe themes, think quickly on the go, and encourage participation (Bedford \& Burgess, 2001, p. 129).

Focus groups certainly offer a way to gather perspectives from a large group of people more quickly than what is possible with individual interviews (Belgrave \& Smith, 1995; Cameron, 2000; Hollander, 2004; Kamberelis \& Dimitriadis, 2005). The rapid amassing of data through focus groups does engender some shortcomings. Indeed, Stewart, Shamdasani, and Rook (2007, p. 12) suggested that focus groups often lack depth because researchers ask too many questions during focus groups and rely too heavily on "direct questions and verbal responses to them." As a result, scholars often overlook or exclude detailed interpretations of the experiences and emotions circulating within focus groups. Furthermore, the possibility for scripting a unitary community and/or dominant personalities performing authority can also arise in these group interview settings, which leads to the silencing of some stories and the liberation of others (Bedford \& Burgess, 2001, p. 125; Belgrave \& Smith, 1995).

Still, the cathartic and empowerment possibilities of focus groups mark a lauded aspect of the method (Goss \& Leinbach, 1996; Neal \& Walters, 2006, p. 188; Skop, 2006). We too found that many of our research participants spoke positively about the focus group experience. For example, Mumtaz ${ }^{5}$ states, "I quite enjoyed the focus group. I got to learn something too" (Interview 207j, FirstGeneration Woman, August 22, 2005, p. 1). The focus groups were lively events with refreshments and time to socialize built into the format. The accent on the mutual benefits of focus groups for researchers and research participants alike corresponds with the assertion that focus groups signal a feminist approach to research (Kamberelis \& Dimitriadis, 2005; Wilkinson, 1999). As Wilkinson (p. 64, italics in the original) explained, focus groups are "a relatively non-hierarchical method; that is, they shift the balance of power away from the researcher towards the research participants."
Attention to possible shifts in power relations in focus groups emerges in another form, namely, the burgeoning interest in the focus group experience itself. Within this literature, scholars examine the micropolitics of the group as they study the interactions between focus group participants and/or between the researcher(s) and the participants. Hollander, for example, suggested that scholars often overlook the various social contexts informing focus groups, even though these are crucial factors in the discussions (e.g., Wilkinson, 1999, p. 67). Highlighting the importance of "associational, status (especially gender), conversational, and relational contexts" (Hollander, 2004, p. 603; see also Pushor, 2008) leads Hollander (p. 606) to argue that social contexts have "implications for both focus group methodology and the interpretation of focus group data." While Hollander offers some advice about how to conduct successful focus groups, the locus of her attention is on the analysis of focus group interactions (see also Pratt, 2000b).

Building upon these themes, Neal and Walters delineated how their positionalities, and the ways that they were "read" by focus group participants, influence focus group conversations. More specifically, the authors "reflect on who we were in relation to rural spaces and the impact and effect that our articulation of this relation had on the collective narratives we were told by those people we talked to" (Neal \& Walters, 2006, p. 181). Analyzing focus group interactions through a reflexive stance firmly situated the authors within the data and the collective knowledge production (see also Easterby-Smith \& Malina, 1999). It also enabled Neal and Walters to draw out the power relations, social dynamics, and performances that framed the focus groups (e.g., Pratt, 2000a). These themes are relevant and crucial to address because, as Kamberelis and Dimitriadis (2005, p. 887) explained, focus groups are "always already engaged in and with real-world problems and asymmetries in the distribution of economic and social capital."

Most scholars recommend using focus groups in tandem with other qualitative or quantitative methods. As focus group findings "are not applicable to a wider population" (Cameron, 2000, p. 87), it makes sense to link and compare insights from focus groups with other forms of data. Focus groups help identify salient themes to probe further, but they do not reveal the extent or generalizability of an issue or allow patterns of responses to arise. Therefore, comparing and contrasting data gathered through focus groups and other methods offers an opportunity to sharpen interpretations (Goss \& Leinbach, 1996; Wight, 1994).

In a different kind of linking of methods, we contend that there is a need to address the ways in which the creation of meaning weaves through focus groups and subsequent interviews. Our focus groups were not "one-off's" in the conventional sense of a one-time meeting of previously unknown participants. In contrast, our focus groups were 
one-time meetings of participants (many of whom knew each other already) who we later interviewed. Thus, the focus group, given its social significance to us and to the Ismaili participants, was not a bounded dialogue but rather the beginning of several conversations and interpretations. Pratt (2000b, p. 11) called for a feminist engagement with focus groups so as to explore the ways that "focus group conversations change depending on where they occur." We extend this notion to suggest that the boundaries of the focus group itself change depending on research design. Thus, examining the understudied implication on data collection of ties between methods merits further attention (Hollander, 2004, p. 629; Hopkins, 2007; Morgan, 2002, p. 152). This acknowledgment drives the following discussion on focus group effects.

\section{Focus Group Effects}

As Team Ismaili members we recognized the possibilities afforded through focus groups and began our fieldwork by conducting four focus groups in a single day, a feat made feasible through teamwork. Our morning consisted of gender-specific focus groups with first-generation Ismailis, and our afternoon included gender-specific focus groups with second-generation Ismailis. A total of 36 people participated in the focus groups. ${ }^{6}$ The focus groups helped us establish rapport with Ismailis and learn more about community norms (Goss \& Leinbach, 1996; Morgan, 2002; Stewart et al., 2007). The focus groups also served as a pilot study for our interview schedule (we began to ascertain whether our questions were relevant) and provided inspiration for new lines of inquiry. We used the focus groups as the primary site for recruiting future interviewees as well. ${ }^{7}$ Just over half of our interviewees also participated in the focus group (Jamal, 2006). ${ }^{8}$

The inclusion of focus group participants in subsequent interviews produced the basis for the noted focus group effects. Working as a team to identify and interrogate these effects compelled us to grapple more concretely with the varying perspectives we encountered and the impact of our linked methods. The focus group effects emerged in numerous forms in the interviews, ranging from the rehearsal of community scripts, to the foreclosure of responses, to the enabling of prepared monologues. ${ }^{9}$ By way of example, $\mathrm{Zul}$ comments, "One question that was brought up in the . . . in the focus group was about intermarriage. [Interviewer: Right, okay.] Now, I am totally against that intermarriage and the reason is quite simple" (Interview 101, FirstGeneration Man, August 8, 2005, p. 25). Zul continues on to offer explicit reasons for why intermarriage is detrimental to the family and community. His clarity of narrative and his unprompted introduction of this topic to the interview all suggest that he planned ahead of time to tell us his position on this issue. In other words, the focus group provided the fodder and frame for $\mathrm{Zul}$ to craft his story. Belgrave and Smith suggest that focus groups encourage the scripting of comments, and $\mathrm{Zul}$ might have translated this type of performance to the individual interview setting. These authors note, "A number of the focus group respondents appeared to be making prepared remarks or playing to the audience" (Belgrave \& Smith, 1995, p. 76). While we anticipated some of this public positioning in the focus groups, we found the appearance of similar actions in the interviews somewhat surprising. Recognizing this feature as part and parcel of focus group effects aided in our analysis of the implications and meanings of such monologues.

Although we imagined that individual interviews would provide space for more divergent narratives to emerge, interviewees often reiterated and verified what they had said in the context of the focus group, as if to reaffirm the "truthfulness" and clarity of those stories. For instance, Amina comments, "That's what I said in the focus group" (Interview 205f, First-Generation Woman, August 16, 2005, p. 23), and Aman concurs, "I think I mentioned this in the focus group" (Interview 304h, Second-Generation Man, August 23, 2005, p. 30). This is not necessarily unusual as most storytelling builds on preexisting narratives and relies on a framework. Schrager (1998, p. 284) claimed that in interviews "most of what is told has been said before in a related form." In our situation, the time period between the focus group and interviews offered a moment for ideas to gain clarity and articulation before the individual interviews. Noting how the focus groups helped give strength to the storytelling prompts us to further highlight the ways that methodological links come to bear in data collection.

The ties between focus groups and interviews surfaced in several other obvious forums as well. For instance, interviewees occasionally questioned us as interviewers, "Remember I mentioned [this] . . . in the focus group?" (Mumtaz, Interview 207j, First-Generation Woman, August 22,2005, p. 17), as if to assess our attentiveness in the focus groups. Mumtaz also sought confirmation and support from us in this comment, itself a fleeting statement that called upon our ability to bear witness to and remember the details of the focus groups. Similar passing comments, such as, "I think we touched on this in our focus group" (Ali-Mohammad, Interview 308, Second-Generation Man, August 1, 2005, p. 33), worked to continuously remind everyone of the connections between the focus group and the interviews.

The prevailing community narratives about Ismailis expressed in the focus groups hovered implicitly in the wings or explicitly took center stage during the interviews. Wight (1994) observed that it matters whether individual interviews precede or follow focus groups. In his study of 
how boys talk about sex, Wight states, "Several young men who recounted their sexual histories to me as if fairly sensitive to their partners' feelings later discussed sex with their class mates in a grossly obscene, objectifying manner" (p. 729). Wight found the greatest difference in presentations of sexuality when he interviewed boys one on one and then held focus groups rather than vice versa. This finding suggests that once a norm has been stated and established within the larger group, individuals are less likely to challenge such norms even in solo interview settings. Although we did not conduct similar methodological comparisons, we found that the focus groups framed subsequent interviews in considerable ways.

The ordering of our methods (focus groups followed by interviews) not only contributed to the sedimentation of shared community norms but it also truncated certain lines of inquiry. For instance, Arianna presupposes that she need not elaborate on living near khana ${ }^{10}$ because the focus groups addressed the topic. She remarks, "We talked about that in the focus groups . . . and yeah, I do think that was a conscious decision, so we were really close and a lot of Ismailis live in that sort of place" (Interview 411, SecondGeneration Woman, August 8, 2005, p. 12). Even though the interviewer probed a bit further, the tacit agreement was that this information was known and already gathered through the focus groups.

In a similar vein, Nasreen describes how the focus group discussion continued on within her household; these conversations subsequently found their way back into the interview. She explains,

Well, I remember one of the questions being, "What do we consider home?," in the focus group, and I was really interested, so I asked my mom what if someone would ask her "what was home for her." She ... she said, "Canada, more specifically Burnaby.". . . and I asked her, "Why," and she said, "Because, you know, we have no family there in Kenya. We have lived here for over thirty years. We've established ourselves here." (Interview 412, Second-Generation Woman, August 13, 2005, p. 1)

In this passage, Nasreen almost preemptively answers the question, "What is home?," by outlining how the focus group prompted her to ask her mom about connections to home (wherever that may be). More importantly, Nasreen begins her interview with this reference to the focus group, thereby establishing a close association between the two methods. She clearly has spent time thinking about and discussing the question of home in the weeks between the focus group and interview. Yet in the interview setting Nasreen chooses to reveal information about her mom rather than herself. Her commentary forecloses the possibility of asking about her own sense of home as a result. Thus, we are left with more detailed data about Nasreen's mom and her connection to home (according to Nasreen) but with little knowledge of Nasreen's personal perceptions. Both Nasreen and Arianna illustrate how focus group effects surfaced in explicit ways: Arianna opted not to address a specific topic because she determined it adequately covered in the focus group, and Nasreen excluded herself from the conversation on home.

Although as interviewers we consistently tried to encourage interviewees to tell their own story or to elaborate upon specific themes, for instance, "We asked you questions during the focus group, I'm sure you remember, about the way you sort of identify or describe yourself, and now it's a chance to maybe give us a more thorough answer about that" (Interviewer speaking with 304h, Second-Generation Man, August 23, 2005, p. 14), our attempts to flesh out certain topics and to establish rapport inadvertently produced another kind of focus group effect. For example, in the following exchange the interviewer relies upon prior knowledge of the interviewee garnered through the focus group. As a result, the interviewer more or less unintentionally answers the very question ("How do you identify?") that she poses:

Interviewer: One question that I skipped over was . . . we talked about in the focus groups and, I think I remember your answer correctly but I should just revisit it quickly, it's about, you know, you're introducing yourself to your neighbor.

Mumtaz: Yes, yes.

Interviewer: Yeah, and, and I think you had said that you would say you're Canadian and then if they said, "well, you know, you know where were you born," or something like that, you would say, "I'm from East Africa"; is . . . is that correct to say?

Mumtaz: Yeah, yeah.

Interviewer: I remember that, yeah. (Interview 207j, First-Generation Woman, August 22, 2005, p. 34)

As this dialogue demonstrates we too helped create focus group effects. At times, we overtly knit together the focus groups and interviews and in other instances we called forth prior knowledge of interviewees. This "insider" knowledge might have provided a comfortable atmosphere for interviewees, but it might have also influenced our ability to hear and solicit new and different responses during interviews (see also Belgrave \& Smith, 1995).

While the focus group effect shaped our data in notable ways, the bind between the focus groups and interviews was not entirely negative or insurmountable. Indeed, for some interviewees, the individual conversations provided a space for voicing different takes on Ismailis (see Hollander, 
2004, for similar outcomes in another research context). For instance, Nuvroza explains, "My experience, from what other people were saying at the focus groups, was a little bit different" (Interview 408n, Second-Generation Woman, August 8,2005 , p. 26). Nuvroza took the opportunity in the interview to narrate how her upbringing diverged from other Ismailis, particularly with reference to her parent's expectations for her. She notes,

It was mostly about good character, and the university expectation was always there. ... My experience from what people were saying at the focus groups was a little bit different in that they never really pressured me, that I had to get straight As or that I had to do well in math or science or specific subjects and, or you know, they would never bribe me for, you know, to get good grades. I would never get any sort of reward, and I would never get any sort of punishment either if I didn't. (Interview 408n, Second-Generation Woman, August 8, 2005, p. 26)

The focus group might have silenced Nuvroza to some extent; yet it also provided an important point of comparison for her subsequent narrative in the individual interview setting.

Aman fleshed out underrepresented themes from the focus group during his interview as well. In response to questions about his sense of home, he states,

I would say that home, home is Canada, . . . but I would say that there is obviously an attachment [to India, Pakistan, and Kenya], and I think in the focus group it didn't come across at all, [italics added] but I do know that there is an attachment, and I can feel it even with the way I want to plan my life. Like, I know it's important for me to go and see India, for some reason, ... I just want to see that region of the world. (Interview 304h, Second-Generation Man, August 23, 2005, p. 17)

Once again the focus groups emerged as an important backdrop through which interviewees juxtaposed or further developed their personal stories. This represents yet another type of focus group effect as the focus group and interview collectively contributed to the production of Aman and Nuvroza's commentaries.

In sum, the focus groups generated a set of shared, if not unanimous, norms and knowledges for researchers and research participants alike (see Kamberelis \& Dimitriadis, 2005 , for another discussion on collective testimonies and shared knowledge). Focus groups also offered time for deeper reflection and conversation about salient themes and questions prior to the interviews. We gathered substantial amounts of data through the focus groups and learned about community expectations through these forums. Using the focus groups as the primary site for recruiting interviewees was ideal in many ways, especially given our constrained research time line. We and the project were known entities to focus group participants, and this might have allowed people to feel more comfortable volunteering for interviews. Moreover, focus group participants might have developed an investment in the success of the project, and therefore, could have offered their time for the next phase of the research in an effort to see the project through.

While there was some ease created through this recruitment strategy, there were also numerous other unanticipated links forged between the focus groups and individual interviews, as the iterations of the focus group effects illustrate above. Yet it bears mentioning that the assorted focus group effects do not necessarily diminish the validity or relevance of our data. On the contrary, these effects compelled us to critically examine the implications of our methodological decisions and to draw out the many perspectives in our archive, thereby expanding our interpretative lenses and extending our engagement with qualitative methods. While we could discuss the "interviewer effects" or the "convener effects" or the ways that our individual biographies and contextual circumstances interweave in the research process, we foreground several different kinds of "focus group effects" because it was through collaborative teamwork that these effects came to light. We collectively spotted links between methods and noted the prevailing dominant and counter narratives. This type of critical engagement with our data and our research design encouraged us to unsettle and question narrow interpretations of Ismailis and to deepen our understanding of the processes and meanings circulating within the community. To further delineate the multiplicity embedded in and produced by our team-enacted methods, we now turn to the second phase of our fieldwork, simultaneous household interviews.

\section{Simultaneous Household Interview Strategy}

The question of whether and how to do household interviews has surfaced as a prominent theme in heteronormative research on the "family" within the last decade (see Valentine, 1999; Wheelock \& Oughten, 1996). Due to prevailing gender assumptions, women have often been the focal study group within family research. The turn toward household interviews occurred in tandem with the call for broadening the scope of analysis to include women and men in discussions of the family, home, and social reproduction. Incorporating men into research designs prompted consideration of whether to interview men and women alone or together (Hertz, 1995; Valentine, 1999). Concerns 
about reproducing power relations and potentially silencing women through joint interviews caused some people to turn away from collective household interviews (LaRossa, Bennett, \& Gelles, 1981; Valentine, 1999). Yet other scholars found that wrestling with the frequently conflicting tales about families evident within joint household interviews sharpened interpretations of family dynamics (Hertz, 1995) and highlighted the power relations underlying couples (Bennett \& McAvity, 1992).

Though our simultaneous household interview strategy builds upon many of these considerations, it represents a distinctive deployment of the method as well. Specifically, we conducted interviews simultaneously with different household members, an impossible strategy for a lone researcher. This approach relied upon what Gerstl-Pepin and Gunzenhauser (2002, p. 40) called "collaborative teaming," as we all individually played an important role in the data collection process. The simultaneous household interview strategy meant that no single rendition of the family and its experiences remained stable. The conversations with household members repeatedly upended and contradicted the tidiness of prevailing narratives of family and community. Moreover, as Hertz (1995, p. 438) explained about research with couples, "Separating the spouses forces them to have to respond without the rehearsed routine." In addition to productively fracturing singular narratives of family and community, our strategy for household interviews marked a compelling method for intergenerational research (Jamal, 2006).

Our team held 47 interviews with 2 generations of respondents; within this sample, we conducted 13 household interviews consisting of 35 individual interviews. Although we generally tried to interview household members at the same time - these are the interviews that we draw upon in this paper-scheduling conflicts sometimes prevented this approach. In such circumstances, we conducted interviews with individual family members on different days. At times, the temporal gaps between interviews had ramifications. For example, one first-generation man equivocated about whether or not he wanted to have his interview included in our archive because of his candor. He worried that his interview transcript might reveal his identity and negatively affect his daughter, who we were also scheduled to interview. He ultimately decided to keep his interview in the archive, but the subsequent interview with his daughter resulted in the study's only "no show." We do not know for sure what happened, but we can surmise that the father's concerns about his interview influenced the daughter's actions. As this example makes plain, simultaneous rather than serial interviews with family members proved to be the most analytically rich and provocative method for us.

To illustrate how the simultaneous household strategy facilitated the procurement of an array of stories, in this section we work through different household perspectives on partnership and marriage. We focus on partnership and marriage because these surfaced as potent themes in the majority of the interviews with both generations of Ismailis. Our intention here is to show the analytical possibilities catalyzed by the simultaneous household interview strategy by outlining moments when family narratives conflict and depart. Rather than posit one account as more "accurate" than another, we focus here on how the differences add depth to our interpretations of salient issues. Just as the focus group effects encouraged us to crack open preconceived notions and seek out a range of perceptions, the simultaneous household interviews brought to light many perspectives and illuminated the silences that often echo through interviews. Once again, the team research context was absolutely fundamental to this technique of interviewing.

\section{Partnership and Marriage}

The interviews reveal different expectations for marriage across generations, genders, and sexualities (see also Grewal, 2009). In the following example, the juxtaposed comments of a mother and son demonstrate how the simultaneous household interview strategy draws attention to various narratives and perspectives. When asked about marriage prospects for her three sons, Almas replies,

Whatever makes them happy, will make me happy. . . . That's none of my business, who they date, who they marry. If they're happy, fine . . I I don't want to interfere. ... That's why, like [son] introduced me to his girlfriend, right? ... . And we went for dinner and she's an Ismaili, okay. "Mom, did you like her?" I said, "Yeah, I like her," but do I have a choice? . . . I like her, I have to like her and, "Did she like me?," I asked him. "Oh yeah, she loved you." But, well, I said, "She doesn't have a choice. I'm your mother" (laughs). Right, she can't refuse me! . . . I always wanted a daughter, so my, whoever they date ... you know whoever it is, it will be my daughter. (Interview $210 \mathrm{~m}$, First-Generation Woman, August 28, 2005, p. 30)

Almas presents herself as comfortable with whomever her sons choose as long as everyone is happy. She notes that she is eager to have a daughter so that is a primary motivation for pairing up her sons.

Galib, one of Almas's sons, however, offers a different explanation of family dynamics and preapproved partners. He recalls that his mom always said,

You can date whoever you want, you can love whoever you want, but the one you marry should be, should be Ismaili. . . . throughout high school when I 
was dating girls ... [ [they were] never Ismaili. (Interview 305m, Second-Generation Man, August 28, 2005, p. 21)

Even though Almas states that she is happy with whoever her sons choose, Galib recalls different norms and expectations set up for himself and his brothers. His mother also holds on to a heteronormative narrative and talks about her sons marrying "girls." In contrast, Galib explains,

My mother's brother, youngest one, is gay, and he lives with his partner in Edmonton. So that broke a lot of walls. He used to live with us, and so they found out, you know, that he was gay, and then my dad threw him out of the house and made him go to counseling . . . there's no word in Gujarati if you're gay. There's no, there's no gay in East Africa, really, you know? (Interview 305m, Second-Generation Man, August 28, 2005, pp. 21-22)

Galib mentioned that his uncle remains closeted within the extended family and community network and then he said,

When I came out at nineteen, . . . [mother] goes, "Who cares?" . . . [in contrast] my dad and I didn't talk for like a year. We didn't talk about it, like we talked, we didn't talk about it. . . . And now he's like my best friend, the biggest supporter, he was in the last Pride Parade. . . . I wasn't even in the last Pride Parade and he was there. (Interview 305m, Second-Generation Man, August 28, 2005, p. 23)

Almas and Galib's interviews complement each other in important ways. Together they add depth to our understanding of this household and reveal the partiality of individual family narratives. Not only do these interviews substantively extend our interpretations of expectations for life partners but also the silence around gay partnerships in Almas' interview and the presence of gay partnerships in Galib's interview exemplify different generational perspectives on what can be discussed with others in private or public contexts. Thus, while these narratives are not necessarily mutually exclusive or contradictory, they remind us of what can be missed or not heard in single interviews with people of only one generation (Jamal, 2006; Vanderbeck, 2007).

Our interviews within another household, that of Abdul, Amina, and their daughter, Aleesha, also expose clear distinctions between the generations in terms of expectations for marital partners and what can be shared in an interview. The absence of certain stories in particular interviews is notable as once again the second-generation interviewee elects to bring up private family matters within the context of the semipublic interview. In the following excerpt, Abdul, a first-generation man, details two important criteria for an appropriate marriage partner:

One, over a period of time make sure . . that person [partner] is willing ... [to] turn, change and become an Ismaili. We have that sort of an example in the family; in ... the community that is not a farfetched idea at all. That, that's number one. Second is . . . if you have children, let them become Ismaili. So, there is a perpetuation there. (Interview 108f, First-Generation Man, August 16, 2005, p. 29)

Although Abdul recognizes that determining the future spouses of his daughters is challenging, noting that his daughters are "grownup individuals with degrees, with wider experience" (Interview 108f, First-Generation Man, August 16, 2005, p. 29), he still specifies the importance of an Ismaili identity within the marriage process. The spouse does not have to initially identify as Ismaili, but ideally the person will "change and become an Ismaili" (Interview 108f, First-Generation Man, August 16, 2005, p. 29). Abdul's rationale is that a unified religious and cultural identity among parents will encourage children to become Ismaili as well. The notion of cultural transmission underscores his perspectives on partners, especially because he wants his "children to stay close to the family, close to our roots as, as an Ismaili" (Interview 108f, First-Generation Man, August 16, 2005, p. 30).

Abdul vacillates in the interview between outlining the importance of marriage as a form of identity maintenance and transmission (this could occur through conversion) and noting that his daughters are cosmopolitan and welleducated women who will make sound decisions. Abdul's narrative suggests that he wants to support his daughters, yet he also feels strong ties to his Ismaili identity and wants to see such connections maintained. Fears of mixed marriages and the related investment in sustaining ethnic, religious, and perhaps implicitly racial norms through marriage emerge in other Muslim immigrant communities as well (see Grewal, 2009).

Amina, a first-generation woman and Abdul's partner, shares some of this ambivalence, although she is much more explicit about her preference for Ismaili husbands. She too registers her concern for future grandchildren and their identities, but she also emphasizes her worry about her daughters' happiness, a sentiment that purportedly transcends religious, ethnic, and cultural boundaries:

Interviewer: When you're thinking about them getting married . . ., what would you hope for both of your girls?

Amina: It would be nice to have an Ismaili guy. I'll tell you that because then they can maintain the religion, 
but it would be hard, I told them [the daughters], for you to marry somebody and say, "You know, I want to go to the mosque." ... It would be hard . . . to say, "Okay, today I have to go, you know, for special prayers because prayer is a very strong part of our culture". . . Plus remember when the kids come that would be another hamper . . . But, if . . . [you] don't find an Ismaili that's okay because I don't want you to find somebody who is not right for you. I want you to find someone who respects you, cares for you, and that you respect and care for and, and have a happier relationship, but if it's not Ismaili uh I guess, I don't know ..., but I think I will be able to accept it.

Interviewer: What about someone, let's say like a white Canadian, if he converted?

Amina: That would be even nice, . . . if he would convert that would be excellent, but what if he doesn't convert? . . . I can see that conflict happening, but still, I guess, you know, I am not imposing anything on them. (Interview 205f, First-Generation Woman, August 16, 2005, pp. 23-24)

Competing narratives emerge in this passage as Amina articulates why it is important for her daughters to marry other Ismailis, on the one hand, and tries to foreground her ability to accept whatever decisions her daughters make and not impose her views upon them, on the other. These different perspectives dovetail with deeply held assumptions about cultural transmission. Amina and Abdul both view marriage within the community as a key facet of cultural maintenance and as the catalyst for Ismaili identity formation within future generations.

Interestingly, what neither Amina nor Abdul mention is that one of their daughters, Aleesha, has already been engaged and then abandoned by her Ismaili fiancé. While this experience resulted in tremendous personal and community embarrassment, it did not seem to unsettle Abdul and Amina's belief in the importance of marriage with an Ismaili man. In our interview with Aleesha she recalled the engagement experience:

I was engaged and I was also not extremely physically healthy. ... I wanted to get better because when you're sick you fight a lot, so there's no point in fighting when I can just stay here [with parents] and get better. So, after a few months I went home and I had, we [she and her fiancé] had bought a house because we thought, you know, if you're engaged why pay rent, just pay it towards the mortgage. ... Came back to an empty house, no furniture, no clothes, no car, no boat, nothing. . . . He had, you know, what identity theft is? Where you know they take your identity ... and credit?... I started to get all these calls and it was very humiliating because I had just finished my engagement. . . . So, I didn't really tell anyone, . . . I started working three jobs. I quit school, actually I didn't quit, I failed out of school because I was working so much and had to pay for this. I mean I didn't buy anything, I just paid. . . . So, I tried to get him [ex- fiancé] back . . . I'm not sure if it's because I really wanted it or because I just needed help. . . . I couldn't handle it anymore and I just said, "I'm leaving." I left my car, my place, gave the keys to a friend and got on the plane, called my parents from Amsterdam and said, "I'm not coming back because this happened." . . . It didn't work out so well because they [parents] stopped talking to me . . . because they thought it was my fault. . . . I was like lost, no money, no house, no education. (Interview 404f, SecondGeneration Woman, August 16, 2005, p. 14)

Aleesha has spent years recovering her identity, paying off her debts, and finishing a university degree. Her family has finally come around to the view that she was not at fault and the family relationships have repaired. Although she notes that the worst of her trials may be over, she still says, "My life is like a train wreck, there's no good part yet. I'm waiting" (Interview 404f, Second-Generation Woman, August 16, 2005, p. 12).

Aleesha's story suggests that for this family concerns about marital partners are not just hypothetical. While Abdul and Amina mention a preference for someone with Ismaili ethnic, cultural, and religious identities, Aleesha's narrative indicates a more complicated relationship between the family members and the experience of marriage. The different silences evident in the three interviews also point to the degree to which community norms and perceptions of privacy inform interview conversations. If we did not do simultaneous interviews with Abdul, Amina, and Aleesha, we may not have gathered these assorted stories and gained insight on how perceived cultural norms underpin stated marital preferences within a household. Thus, we might not have had such a window into some of the many facets that comprise a family.

\section{Postinterview Team Dialogues}

The simultaneous household interviews made clear that families are neither hermeneutically sealed entities nor consistent and unified respondents when speaking of the "household." This daily reminder prompted many lively postinterview dialogues among Team Ismaili. Through such conversations, we began to collaboratively interrogate the diverse responses from family members. These dialogues immersed us in the fluid dynamic of data collection and analysis, helped refine and nuance our interview schedule 
as we quickly learned what themes we needed to probe further in future interviews, and firmly marked our role in knowledge production as our recorded postinterview dialogues became a new form of data (i.e., Burgess et al., 1988). Pushor (2008, p. 92) noted, "Collaborative research invites rich dialogue between and among individuals." We certainly found this to be the case in our debriefing sessions. Indeed, the postinterview dialogues signify an important, though not initially planned, method in our fieldwork and indicate once again the methodological opportunities embedded within team research.

We began recording and transcribing our postinterview debriefings to capture our immediate reactions to the starkly different narratives we collected. For example, here James, Arif, and Serin rehash their interviews with Aleesha, Amina, and Abdul:

Arif: Her parents didn't talk to her for six months after her marriage broke because it was a huge embarrassment. ... So, they couldn't take it and didn't talk to her ... . she talked more about her emotions and what happened to her and how it caused a huge rift within the family.

James: Okay, did you get any of this Serin? Because I got none of that.

Serin: No.

James: And when I asked him about marriage and dating and the expectations of Ismaili, non-Ismaili, like he didn't even bring that up! Why ... not bring that up?

Arif: Yeah, I don't know. When it came to dating and marriage she, she's still not allowed to date, and she's thirty.

James: That's not what he said.

Arif: She's thirty, and she's never been allowed to date and whenever she did date she had to do it behind their backs.

James: Oh my gosh.

Arif: . . . and in terms of marrying a non-Ismaili it was, it was a humongous issue in high school and in university, but now the mom seems more lenient but the dad's like "no way"!

James: Well, . . . he said . . . "It's whatever makes them [the daughters] happy" (August 16, 2005).

Having the opportunity to instantly "replay" the interviews through our conversations added an invaluable dimension to our fieldwork. The various stories consistently destabilized assumptions about Ismailis and worked to sharpen our analyses of intergenerational relations, identity expressions, and the Ismaili community more generally. They also reminded us that our methods were not simply techniques that we used to collect information. On the contrary, our methodological decisions significantly shaped our research process and findings. As James states in another postinterview dialogue, "If we did one interview in this home we would have lost a million stories because you put the two together and you get this, you know, something interesting . . . you know, these conflicting stories and so it's kind of interesting" (August 11, 2005).

\section{Conclusions}

The team research context directly informed our methods and thus served as a critical foundation for this examination. We might not have noticed the focus group effects if we were not consistently engaged in group discussions as researchers and in the collaborative analysis of data. Similarly, the technique of the simultaneous household interviews could not have happened if we each worked alone. The assortment of family narratives we gleaned through the simultaneous interviews subsequently inspired the postinterview dialogues, another method that would not have been possible for a sole researcher. Through the actual process of, and reflection upon, our fieldwork, we have found that collaborative team research "requires a different thoughtfulness about research design and methods as well as research relationships" (Pushor, 2008, p. 94).

Gathering data through several modalities repeatedly revealed the uniqueness of all stories about Ismailis. Thus, our sense of what it means to be an Ismaili in Vancouver is far from singular. While tales might overlap or diverge, they were never uniform. Recognizing this multiplicity prompted an ongoing dialogue between researchers and the data, conversations that resulted in a stance of critical reflexivity (see also Easterby-Smith \& Malina, 1999, for commentary on cross-cultural collaborations and critical reflexivity). For us, then, pulling common qualitative methods through the team research context broadened and deepened our data collection in unanticipated and exciting ways. It also brought to light some of the underlying feminist politics of our research team as our methods encouraged relational and multiple frames of interpretation and presentation (Kamberelis \& Dimitriadis, 2005, p. 898).

Amassing an archive shot through with fissures and instabilities of coherence might point to some shortcomings with the data and subsequent analysis, but we find significant opportunity and possibility in this situation. Our archive encompasses ambiguities and contradictions, and therefore, upends any attempt to reify or categorize Ismailis in totalizing terms; indeed, "The lack of completeness in ... testimony is not a defect that could be remedied by more preciseness on the part of the teller" (Schrager, 1998, p. 295). We are keenly aware of dominant narratives and the silences that reverberate throughout the focus groups and household interviews. These are all stimulating lines of 
inquiry to further examine as we continue to delve into the migration and settlement processes of Ismailis in Canada.

Studies of immigrant communities and associated perspectives on family and community norms and experiences track a continually moving and transforming "target." Communities evolve, so we need to persistently refine our methods as well. Our study on Ismailis suggests that using focus groups and household interviews in collaborative team research is one avenue for contributing to such refinement. Indeed, the confluence of our methods and the process of using them in a team research context compel us to reflexively grapple with the meaning of our data and to query our ongoing entanglement with knowledge production.

\section{Authors' Note}

The authors would like to thank the editors and reviewers for constructive comments on earlier versions of this article. We also extend our gratitude to Dr. David Ley (organizer) and the participants of the Pacific Northwest Immigration Symposium held in Vancouver, British Columbia, Canada, in 2006, for engaging with our ideas as we began to imagine this manuscript. This research is based on work supported, in part, by a SSHRC social cohesion grant and a National Science Foundation graduate research fellowship. Finally, we thank the Ismaili community in Vancouver for welcoming us into their homes and lives. Please address correspondence to Serin D. Houston, Department of Geography, Syracuse University, 144 Eggers Hall, Syracuse, NY 13244; e-mail: sdhousto@maxwell.syr.edu.

\section{Notes}

1. We dubbed ourselves "Team Ismaili" after one of our initial research meetings when we crystallized our collective commitment to the project.

2. Ismailis are a sect of Shia Muslims spiritually led by the Aga Khan, a living Imam. The term Ismaili refers to a religious identity that finds expression in an array of national and, to a lesser extent, ethnic contexts.

3. The first-generation men and women participants in our study were born in Uganda, Kenya, and Tanzania. The majority of these individuals left East Africa in the 1970s; others followed in the 1980s and early 1990s. While Idi Amin, former president of Uganda, ordered the exile of Asian Africans in 1972, related social processes prompted Asian Africans to flee Kenya and Tanzania. Specifically, the widespread fear caused by the turn of events in Uganda and the growing diasporic community of Ismailis in Canada induced many Ismailis to leave East Africa. At the time of our fieldwork, first-generation immigrants in our study ranged in age from late 40 s to early 70 s. These participants held jobs in an array of economic sectors, such as real estate, education, and service industries. The majority of second-generation Ismailis (immigrants' children) were born in British Columbia. Most of these individuals were in the midst of pursuing university and other advanced degrees.
Second-generation participants reported being between the ages of 18 and 30 at the time of the research. In short, although participation in our study points to a shared community-minded mentality among our participants, a host of differences existed within the group as well.

4. In this context, we use the terms household and family relatively interchangeably. We fully acknowledge that not all families share a household and vice versa. Within the context of this study, however, the households were made up of families. Thus, we use both terms to describe the interviewees.

5. This, as with all names in this article, is a pseudonym.

6. Focus groups included the participation of 12 first-generation men, 8 first-generation women, 8 second-generation men, and 8 second-generation women. We had both Ismaili and nonIsmaili coconveners facilitating the focus groups.

7. Once we were in the midst of interviewing, we realized how our recruiting methods skewed our sample, especially evident in the crossover between focus group and interview participants and the general pull toward community and volunteerminded Ismailis. In other words, alternative narratives and experiences from the periphery did not, for the most part, make it into our research archive. We attempted to broaden our recruiting through running an ad in The Courier newspapers (free newspapers delivered to homes throughout the Lower Mainland). Unfortunately, these ads did not produce many eligible interviewees.

8. In total, we interviewed 14 first-generation men, 9 firstgeneration women, 10 second-generation men, and 14 secondgeneration women.

9. Although our decision to recruit interviewees primarily through the focus groups created the possibility for focus group effects, it bears mentioning that the Ismaili community is relatively small and tight-knit; thus, concern as to how news and opinions would travel might have also shaped interactions in all quarters. We could assure confidentiality with how we handled the data, but we could not control other subsequent conversations. As Hollander (2004, p. 615) explained, "Neither the researcher nor the individual participant can fully control information disclosed during a discussion. Participants are likely aware of these risks and modify their participation accordingly." This might have been a factor in the scripting that we witnessed.

10. Loosely translates as mosque.

\section{References}

Bedford, T., \& Burgess, J. (2001). The focus-group experience. In M. Limb \& C. Dwyer (Eds.), Qualitative methodologies for geographers: Issues and debates (pp. 121-135). New York: Oxford University Press.

Belgrave, L., \& Smith, K. (1995). Negotiated validity in collaborative ethnography. Qualitative Inquiry, 1, 69-86.

Bennett, L., \& McAvity, K. (1992). Family research: A case for interviewing couples. In J. Gilgun, K. Daly, \& G. Handel 
(Eds.), Qualitative methods in family research (pp. 75-93). Newbury Park, CA: Sage.

Breen, R. (2006). A practical guide to focus-group research. Journal of Geography in Higher Education, 30, 463-475.

Burgess, J., Limb, M., \& Harrison, M. (1988). Exploring environmental values through the medium of small groups: Theory and practice. Environment and Planning A, 20, 309-326.

Cameron, J. (2000). Focussing on the focus group. In I. Hay (Ed.), Qualitative research methods in human geography (pp. 83-102). New York: Oxford University Press.

Conradson, D. (2005). Focus groups. In R. Flowerdew \& D. Martin (Eds.), Methods in human geography (pp. 128-143). Harlow, UK: Pearson.

Easterby-Smith, M., \& Malina, D. (1999). Cross-cultural collaborative research: Toward reflexivity. The Academy of Management Journal, 42(1), 76-86.

Gerstl-Pepin, C., \& Gunzenhauser, M. (2002). Collaborative team ethnography and the paradoxes of interpretation. International Journal of Qualitative Studies in Education, 15, 137-154.

Goss, J. (1996). Introduction to focus groups. Area, 28, 113-114.

Goss, J., \& Leinbach, T. (1996). Focus groups as alternative research practice: Experience with transmigrants in Indonesia. Area, 28, 115-123.

Grewal, Z. (2009). Marriage in color: Race, religion and spouse selection in four American mosques. Ethnic and Racial Studies, 32, 323-345.

Hafernik, J., Messerschmitt, D., \& Vandrick, S. (1997). Collaborative research: Why and how? Educational Researcher, 26(9), 31-35.

Hertz, R. (1995). Separate but simultaneous interviewing of husbands and wives: Making sense of their stories. Qualitative Inquiry, 1, 429-451.

Holbrook, B., \& Jackson, P. (1996). Shopping around: Focus group research in North London. Area, 28, 136-142.

Hollander, J. (2004). The social contexts of focus groups. Journal of Contemporary Ethnography, 33, 602-637.

Hopkins, P. (2007). Thinking critically and creatively about focus groups. Area, 39, 528-535.

Houston, S., Hyndman, J., Jamal, A., \& McLean, J. (2006). Methodologically becoming too. Pacific Northwest Immigration Symposium, Vancouver, BC.

Houston, S., Hyndman, J., McLean, J., \& Jamal, A. (in press). Still methodologically becoming: Collaboration, feminist politics, and "Team Ismaili." Gender, Place and Culture.

Hyndman, J., \& Walton-Roberts, M. (2000). Interrogating borders: A transnational approach to refugee research in Vancouver. Canadian Geographer, 44, 244-258.

Jamal, A. (2006). Linking migration and education across generations: Ismailis in Vancouver. MA thesis submitted to Department of Geography, Simon Fraser University.

Kamberelis, G., \& Dimitriadis, G. (2005). Focus groups: Strategic articulations of pedagogy, politics, and inquiry. In N. Denzin \&
Y. Lincoln (Eds.), The Sage handbook of qualitative research (3rd ed., pp. 887-907). Thousand Oaks, CA: Sage.

LaRossa, R., Bennett, L., \& Gelles, R. (1981). Ethical dilemmas in qualitative family research. Journal of Marriage and the Family, 43, 303-313.

Longhurst, R. (1996). Refocusing groups: Pregnant women's geographical experiences in Hamilton, New Zealand/Aotearoa. Area, 28, 143-149.

McLean, J., Friesen, C., \& Hyndman, J. (2006). The first 365 days: Acehnese refugees in Vancouver (RIIM Working Paper \#06-07). Available at http://riim.metropolis.net.

Morgan, D. (1996). Focus groups. Annual Review of Sociology, $22,129-152$.

Morgan, D. (2002). Focus group interviewing. In J. Gubrium \& J. Holstein (Eds.), Handbook of interview research: Context and method (pp. 141-160). Thousand Oaks, CA: Sage.

Neal, S., \& Walters, S. (2006). Strangers asking strange questions? A methodological narrative of researching belonging and identity in English rural communities. Journal of Rural Studies, 22, 177-189.

Pang, C. (1998). Invisible visibility: Intergenerational transfer of identity and social position of Chinese women in Belgium. Asian and Pacific Migration Journal, 7, 433-452.

Pratt, G. (2000a). Research performances. Environment and Planning D: Society and Space, 18, 639-651.

Pratt, G. (2000b). Studying immigrants in focus groups (RIIM Working Paper \#00-18). Available from http://riim.metropolis .net.

Pushor, D. (2008). Collaborative research. In L. Givens (Ed.), Sage encyclopedia of qualitative research methods (pp. 91-94). Thousand Oaks, CA: Sage.

Schrager, S. (1998). What is social in oral history? In R. Perks \& A. Thomson (Eds.), The oral history reader (pp. 284-299). New York: Routledge.

Skop, E. (2006). The methodological potential of focus groups in population geography. Population, Space and Place, 12, 113-124.

Stewart, D., Shamdasani, P., \& Rook, D. (Eds.). (2007). Focus groups: Theory and practice. Thousand Oaks, CA: Sage.

Valentine, G. (1999). Doing household research: Interviewing couples together and apart. Area, 31, 67-74.

Vanderbeck, R. (2007). Intergenerational geographies: Age relations, segregation and re-engagements. Geography Compass, $1,1-22$.

Wheelock, J., \& Oughton, E. (1996). The household as a focus for research. Journal of Economic Issues, 2, 143-159.

Wight, D. (1994). Boys' thought and talk about sex in a working class locality in Glasgow. The Sociological Review, 42, 703-737.

Wilkinson, S. (1999). How useful are focus groups in feminist research? In R. Barbour \& J. Kitzinger (Eds.), Developing focus group research: Politics, theory and practice (pp. 64-78). Thousand Oaks, CA: Sage. 


\section{Bios}

Serin D. Houston is a PhD candidate in the Department of Geography at Syracuse University. Her current research focuses on contemporary place-making practices in Seattle, Washington.

Jennifer Hyndman is an associate professor of geography at York University in Toronto. Her research interests include political geographies of conflict and displacement as informed by feminist thought.
James McLean is a PhD candidate in the Department of Geography at York University. His current research explores identity and belonging among "second-generation" Muslims in Canada.

Arif Jamal is a border services officer for Canada Border Services Agency. His research interests include the geographies of migration, identity, and intergenerational relations. 